\title{
LAS GUERRAS OLVIDADAS DEL PERÚ: FORMACIÓN DEL ESTADO E IMAGINARIO NACIONAL ${ }^{1}$
}

Cecilia Méndez G.

\author{
Carla Granados Moya
}

\begin{abstract}
RESUMO
A diferencia de otros países americanos, el Perú carece de una memoria nacional de sus guerras civiles decimonónicas. Estas han sido opacadas por la avasalladora memoria de la Guerra del Pacífico, que el Perú y Bolivia perdieron ante Chile (1879-1883). El presente ensayo se propone rescatar del olvido a las guerras civiles peruanas del siglo XIX, empezando por las guerras de la independencia. Las preguntas que planteamos están motivadas por la guerra reciente que desató el Sendero Luminoso entre 1980 y fines de la década de 1990, en la que los campesinos andinos asumieron las funciones represivas del Estado al tomar las armas para derrotar a la insurgencia senderista. Esta situación exhibe interesantes paralelos con las guerras civiles del siglo XIX. Proponemos que el estudio de las guerras civiles decimonónicas del Perú, a la luz de la reciente guerra interna, ofrece una oportunidad fecunda para discutir las nociones de ciudadanía y pertenencia, la relación entre guerra y la constitución del Estado, así como los alcances y límites del concepto weberiano del Estado como el ente que monopoliza la violencia legítima. Subrayamos la importancia de la organización civil de las poblaciones rurales en el devenir de la guerra y, más ampliamente, en la construcción del Estado.
\end{abstract}

PALAVRAS-CHAVE: Peru; guerra; guerra civil; identidade nacional; século XIX; Estado nacional.

\begin{abstract}
"Y nosotros [...] que hizimos más de lo que debíamos, es preciso decirlo, militar a nuestra costa, y que habiendo quitado esta piedra de escándalo de la nación, hemos reducido al orden y a sus deberes a los rebeldes [...]" (Pobladores de San Miguel y Chilcas, Ayacucho, 1831 (AGN, 1831)).

"Sendero ha entrado otra vez a Chungui desde Marzo del 2009. Entonces, con los ronderos nos organizamos. Como policía nacional, como ejército estamos actuando" (JIMÉNEZ, 2009) ${ }^{2}$.
\end{abstract}

\section{MEMORIAS AUSENTES}

Este ensayo propone una exploración del proceso de formación del Estado republicano en el Perú a través de sus guerras civiles del siglo XIX y, más específicamente, a través de la participación de las poblaciones rurales en dichas guerras. Como hemos discutido en otras oportunidades, en las

${ }^{1}$ La investigación que sustenta este artículo fue posible, en parte, gracias a la financiación del Senado Académico y el Interdisciplinary Humanities Center de la Universidad de California en Santa Bárbara. Su redacción fue concluida gracias a una beca del Stanford Humanities Center. A todos ellos nuestro reconocimiento. primeras décadas republicanas estas guerras empezando por las campañas de la independencia - se convirtieron no sólo en un vehículo de "ascenso social" sino en una instancia a través de la cual los pobres del campo podían negociar sus derechos y obligaciones para con el Estado, es decir, su condición ciudadana. En esta oportunidad 
queremos ir un poco más allá y sugerir que las poblaciones rurales que participaron en las guerras civiles no sólo lo hicieron con las armas sino que ejercieron tareas de gobierno y control social que fueron claves en el proceso de formación del Estado nacional.

A diferencia de otros países americanos, el Perú no recuerda sus guerras civiles del siglo XIX. Mientras las identidades políticas y los imaginarios nacionales del siglo XX de países como Estados Unidos, Argentina, Colombia, o Uruguay han sido marcados por la memoria de sus guerras civiles del XIX, nada semejante ha ocurrido en el Perú ${ }^{3}$. En Colombia, por ejemplo, los partidos Liberal y Conservador, que se enfrentaron en varias guerras durante el siglo XIX, continuaron su historia de disputas a lo largo del siglo $X^{4}$. En Argentina la proverbial rivalidad decimonónica entre unitarios $\mathrm{y}$ federales también se reeditó en el siglo $\mathrm{XX}$, mediante la rememoración peronista de los célebres caudillos federalistas Facundo Quiroga y Chacho Peñaloza y de sus ejércitos de montoneros. Incluso México, a pesar de su masiva revolución del siglo XX, rastrea las raíces de su liberalismo en las guerras de la Reforma y en el venerado Benito Juárez. Por su parte, los Estados Unidos, donde la bandera de los confederados en la guerra de secesión, que es un símbolo proesclavista por excelencia, no sólo sigue flameando en los estados del sur hoy día, sino que forma parte del sentido de identidad regional de muchos blancos del sur, ciertamente no sin controversia.

La amnesia de las guerras civiles decimonónicas en el Perú no se debe a la ausencia de conflicto. Entre 1820 y 1842 el país pasó por catorce años de guerra, según Basadre (1983). Posteriormente hubo al menos tres guerras civiles de alcance nacional (1854-1855, 1865 y $1894-$ 95). Ninguna de ellas ha sido estudiada como tal ${ }^{5}$. Más aún, pese a que desde la proclamación de la

\footnotetext{
3 Sobre guerras civiles y revoluciones en América Latina durante el siglo XIX, la literatura es abundante. Para algunos ejemplos cf. Zeitlin (1984), López-Alvez (2000), Sánchez y Aguilera (2001), Earle (2002), Paz (2007) y Sabato (2008).

4 Sobre el siglo XIX en Colombia, cf. Prado Rueda (2004) y Sanders (2004).

5 Una excepción para 1895 es Jacobsen (2002). Cf. también Escobar Ohmstede y Falcón (2002).
}

independencia en 1821 hasta el final del siglo XIX, salvo dos breves interregnos, el Perú estuvo gobernado por líderes militares, la historiografía del periodo ha dedicado más atención a estos momentos excepcionales de gobierno civil particularmente al gobierno del civilismo, 1872$1876^{6}$ - que a ocho décadas de gobiernos militares, marcados por enfrentamientos armados.

Las guerras civiles decimonónicas peruanas han sido opacadas por la guerra del Pacífico, que el Perú y Bolivia perdieron ante Chile (1879. 1883). Como el historiador Manrique señaló alguna vez, la memoria de la Guerra del Pacífico ha tenido en el Perú mayor peso en la formación de sentimientos nacionalistas y ha ofrecido un sentido de identidad nacional más prominente que la memoria de las guerras de independencia. De esta manera, una guerra internacional, que tuvo el carácter de excepción, ha moldeado la agenda de los historiadores y el imaginario nacional peruanos en mayor grado que las guerras civiles, que fueron la norma.

La coloquialmente llamada "guerra con Chile" constituye quizá el único conflicto bélico en que el nacionalismo de Estado converge con sentimientos nacionalistas populares. El hecho de que esta guerra involucrara a todas las clases sociales y a vastas regiones del Perú, tanto en la costa como en la sierra - aunque menos en el oriente - puede explicar, en parte, la persistencia de su huella a través de las generaciones.

Sin embargo, como bien sabemos, la memoria histórica nunca es meramente espontánea. Para que perdure públicamente exige la intermediación del Estado a través de monumentos, conmemoraciones, textos escolares, mapas e iconografía oficial. Como hemos sugerido en otros textos, el hecho de que la memoria de la guerra con Chile haya sido activamente promovida desde

\footnotetext{
${ }^{6}$ El gobierno del Partido Civil llegó al poder en 1872 con su fundador, Manuel Pardo, primer presidente civil del Perú. Existe una abundante literatura sobre Pardo y el civilismo (cf. MCEVOY, 1997; 2004; 2007; MÜCKE, 2004; MONSALVE, 2005). Valga acotar que muy recientemente McEvoy ha incursionado en temas militares del periodo inicial de la República con una valiosa compilación de cartas que no hemos podido aprovechar lo suficiente por haberse publicado cuando nuestro ensayo ya estaba casi concluido (cf. MCEVOY \& RENIQUE, 2010).
} 
el Estado podría deberse a que es la guerra en que las clases altas peruanas, especialmente la oligarquía de la costa y de Lima, perdieron más que en ningún otro conflicto (MÉNDEZ G., $2010)^{7}$.

Como contrapunto y bajo una bandera explícitamente antiologárquica, antiimperialista y pro-campesina, el general Juan Velasco Alvarado instauró oficialmente la memoria de Túpac Amaru II, durante su gobierno militar correspondiente al periodo de 1968 a 1975. De esta manera se distanció del recuerdo de la guerra con Chile y, en su lugar instauró oficialmente la memoria del cacique indígena, quien entre 1780 y 1781 había liderado desde Cuzco la rebelión más devastadora que hubo contra el orden español en América antes de la independencia.

Velasco otorgó a la imagen de Túpac Amaru una prominencia que hasta entonces nunca había tenido en el discurso público de Lima, y que nunca volvió a adquirir de allí en adelante. Lo convirtió en el emblema de la revolución militar, icono de los programas sociales del gobierno principalmente de la reforma agraria - y en el "héroe nacional" por antonomasia, en tanto que precursor de la independencia contra España. Irónicamente, mientras el gobierno militar de Velasco reivindicó a una figura indígena en el panteón oficial de héroes nacionales, los gobiernos civiles que le siguieron reivindicaron, en su lugar, la guerra perdida ante los vecinos del sur.

Debido a su contenido violento, su composición étnica mayoritariamente indígena, y su mensaje antiespañol, la memoria de la rebelión liderada por el cacique cuzqueño ha suscitado incomodidad entre las clases altas peruanas y en particular entre las élites criollas de Lima. Esta incomodidad se ha manifestado como un silencio historiográfico que puede rastrearse desde el célebre Mercurio peruano de 1790 hasta al menos

\footnotetext{
7 El silencio historiográfico limeño en torno a Túpac Amaru se quebró en las décadas de 1940 y 1950 cuando las obras monográficas de los historiadores Lewin y Valcárcel - significativamente, un cuzqueño y un argentino - contribuyeron a consagrar al cacique cuzqueño como "precursor de la independencia", no sin haber previamente depurado su rebelión de sus connotaciones violentas, según Cahill (1999). Muy probablemente estas obras dieron a Velasco el capital intelectual necesario para proceder a la consagración oficial del héroe a fines de la década de 1960 .
}

la década de 1940. No deja de ser significativo que las únicas historias de síntesis decimonónicas que dedican al menos un capítulo a esta rebelión fueran escritas por extranjeros (Markham y Lorente), por autores provincianos, especialmente cuzqueños y por autores militares. Tal es el caso del general historiador Manuel de Mendiburu, cuyo Diccionario histórico-biográfico del Perú, de 1890, dedica un largo acápite a Túpac Amaru, basándose en gran parte en el recuento de Markham (MENDIBURU, 1890; cf. también MÉNDEZ G., 2008). Dada esta larga historia de silencios, la adopción oficial de Túpac Amaru como símbolo nacionalista en la era de Velasco, puede ser considerada subversiva, aun cuando haya tenido un carácter oficial.

No sería descabellado suponer que la Gran Rebelión, como se llamó a la rebelión de Túpac Amaru en su tiempo, haya jugado en el Perú un papel análogo al de las guerras civiles decimonónicas de otros países americanos, por lo menos en cuanto a dos aspectos claves, es decir, la fricción regional y el componente de tensión étnica.

\section{GUERRAS CIVILES Y LAFORMACIÓN DEL ESTADO}

Opacadas por las incómodas - y usualmente reprimidas - memorias de una sublevación indígena de fines del siglo xviII, y por una prolongada invasión externa que devastó el país hacia el final del siglo xIx, las guerras civiles del siglo XIX en el Perú se presentan en apariencia como un objeto de estudio irrelevante. Sin embargo, no lo son. Su importancia está dada por el desafío que nos presenta nuestra guerra civil más reciente, aquella lanzada por Sendero Luminoso entre 1980 y fines de la década de 1990, contra el Estado y la sociedad peruanos. Esta guerra interna, presumiblemente la más devastadora en la historia republicana, nos exige replantear el pasado, formulándole nuevas preguntas.

El presente artículo constituye un paso en esa dirección ${ }^{8}$. Intentamos, en otras palabras, reactivar la memoria de las olvidadas guerras

\footnotetext{
8 Tal revaloración ya ha empezado a tener lugar como lo atestigua el trabajo en curso de Jacobsen sobre la revolución de Piérola, que se dio entre 1895 y 1899.
} 
civiles del Perú en el siglo xIX a la luz del conflicto armado reciente. Se trata de un avance preliminar de un proyecto mayor dedicado a estudiar la relación histórica entre los militares y las poblaciones campesinas e indígenas y el papel de la guerra en el sistema político.

En tanto es posible argumentar que las guerras de la independencia sentaron el patrón con el que se llevarían a cabo las guerras civiles subsiguientes, creo correcto considerarlas también nuestras primeras guerras civiles del periodo - casi - nacional. Esta consideración se opone a aquellas tendencias de la historiografía latinoamericana que denominan "guerra civiles" a las guerras de la independencia para subrayar el faccionalismo, las fracturas étnicas y sociales y la "ausencia de nacionalismo" y de "Estado"9. Nuestro análisis se centra, por el contrario, en el examen de tales guerras como parte de los procesos más tempranos de la formación del Estado nacional.

Esta forma de abordar las guerras civiles se inspira, en parte, en el célebre planteamiento de Charles Tilly, acerca de la estrecha interrelación entre la guerra y la formación del Estado (TILLY, 1985) ${ }^{10}$, que se opone a la tendencia generalizada de asociar a las guerras civiles únicamente con desgobierno y anarquía. Nuestro trabajo, en cambio, observa cómo la guerra sostiene, delimita - y no sólo desafía - al Estado. En este sentido discrepamos de la interpretación del sociólogo Centeno, quien en un vasto estudio dedicado al tema concluye que la interrelación entre guerra y formación del Estado señalada por Tilly no es válida para América Latina. Centeno escribe que "después de las guerras de la independencia el conflicto militar desaparece como fuente de legitimación del Estado" (CENTENO, 2002, p. 191). Contrariamente, sin embargo, la guerra no fue sólo el método más común para tomar el

\footnotetext{
9 Por ejemplo ver Bonilla y Spalding (1972) y Bonilla (1981) con respecto al Perú. Para otros enfoques a nivel de América Latina, cf. Earle (2002).

10 A diferencia de Tilly, que se concentra en las guerras externas que enfrentaron a los Estados europeos en el siglo XVII, en competencia por espacios y mercados coloniales (lo que Marx llamó el proceso de "acumulación primitiva" de capital), analizamos las guerras civiles peruanas en un contexto de escasa agresividad externa y contracción de mercados internos.
}

control del Estado después de la independencia, sino una forma legítima de hacer política ${ }^{11}$. Más aún, la guerra como mecanismo de acceso al Estado fue lo que diferenció las nociones decimonónicas post-independientes de Estado y política con respecto a aquellas que se habían tenido en la era colonial ${ }^{12}$. Pero este mismo factor diferenció el Estado del siglo XIX del Estado del siglo $\mathrm{XX}$, porque fue en el transcurso de esta centuria que un ejército profesional centralizado, ahora en comando del monopolio de la fuerza, iría relegar las guerrillas y montoneras que pudieran emerger el reino de la ilegitimidad; esto es, hasta que la guerra de Sendero Luminoso revirtió al país a una situación de guerra civil análoga a la del siglo XIX. Asimismo, a diferencia de las guerras más modernas, que son libradas por los "especialistas en la guerra", las guerras del XIX exigieron el concurso organizado de la población civil, ya que las propias fuerzas del

11 Parafraseando a Sharma y Gupta, "las fronteras del Estado se constituyen como resultado del ejercicio del poder", en este caso, a través de la guerra (BARRAGÁN \& WANDERLEY, 2009). Dicho en otros términos, concebimos al Estado como un lugar en disputa: el lugar de la lucha por el monopolio de la violencia legítima (Weber).

12 Cecilia Méndez ha expuesto esta idea con anterioridad: "In the colonial period, obviously but worth keeping in mind, no such struggles for control of the state occurred between rival factions. So-called anticolonial rebellions pursued reform rather than state takeover and had no legitimate place within the framework of the imperial polity. Conversely, early republican politics were marked by permanent strife over state control; this struggle, moreover, defined much of the state's political fabric through that period. Beyond all other claims political factions seeking legitimacy first and foremost laid claim to the state" (MÉNDEZ G., 2005, p. 237) ["No período colonial, obviamente mas digno de ter em mente, não ocorreram tais lutas pelo controle do Estado entre as facções rivais. As assim chamadas rebeliões anticoloniais perseguiram reformas mais que a tomada do Estado e não tinham posição legítima no quadro do ordenamento político imperial. Por outro lado, a política republicana inicial era marcada pela permanente discórdia a respeito do controle do Estado; essa luta, além disso, definiu muito da estrutura política do Estado ao longo do período. Além de todas as outras pretensões políticas, as facções que procuravam legitimidade em primeiro lugar e antes de mais nada tinham pretensões sobre o Estado" - nota dos revisores]. Otras obras relevantes relacionadas de Méndez G. son: Méndez G. (2001; 2002; 2006); para una versión revisada y expandida de este texto cf. Méndez G. (2009). 
"ejército de línea" (es decir, el ejército regular) eran insuficientes ${ }^{13}$.

\section{GUERRA Y GOBIERNO}

Los oficiales del ejército del siglo XIX dependían de comunidades, principalmente rurales, para hacer la guerra. Dicha dependencia tuvo lugar desde los niveles más básicos hasta los más estratégicos. Esto exige trasladar el examen de la política del ámbito formal, doctrinario y puramente discursivo, al ámbito material, pragmático y cotidiano, que ha sido el más descuidado en los análisis.

Las guerras decimonónicas no hubieran podido pelearse en un desierto como pueden hacerlo las guerras modernas. Los soldados de hoy pueden descansar en su propia infraestructura, y en el suministro, por ejemplo, de comida empacada que les puede ser arrojada desde un helicóptero. Los oficiales mejor calificados del siglo XIX, en cambio, debían calcular en su estrategia rutas y lugares de campamento cercanos a centros poblados bien provistos, lo cual suponía estar en buenos términos con las poblaciones. Las cartas de los altos oficiales durante la guerras de la independencia están llenas de admoniciones a sus subalternos para salvaguardar la reputación de sus ejércitos ante las poblaciones, pues eran en conscientes que la guerra no se ganaría "contra la opinión de los pueblos"; existía un especial énfasis en el buen trato a los "naturales"14. Claro que estas instrucciones no siempre se cumplían

13 El ejército regular alude al ejército profesional de hoy, es decir, soldados de tiempo completo comandados por oficiales. En el siglo XIX lo que hoy se conoce como "ejército regular" era denominado "ejército de línea".

14 Por ejemplo, el 25 de octubre de 1821 el General San Martín escribía, desde Lima, a Toribo Dábalos, Comandante Militar de la Provincia de Canta: "He dispuesto que Ud. se encargue del mando militar de la provincia de Canta y su jurisdicción, en razon de su buena comportación y trato amable que tiene con esos naturales", en Dunbar Temple (1971, p. 419). Por su parte, el General Juan Antonio Álvarez de Arenales señalaba al Gobernador Intendente de Tarma, Coronel Francisco de Paula Otero, que "alli se pueden obrar y hacer mucho los indios bien colocados en las dos alturas del estrecho, con galgas y hondas, sin riesgo de perder gente por nuestra parte, con tal que los indios sean conducidos con la politica y buen modo, que exige el carácter pues en esto se debe poner todo el con ato conveniente y que V.S. no ignora" (DUNBAR TEMPLE, 1971, p. 224). y los pobladores reaccionaban contra el abuso, lo que llevó a los oficiales a flexibilizar sus estrategias. Por ejemplo, el General Gamarra, conocido por su autoritarismo y despotismo, se vio obligado a abolir, a fines de la década de 1830 , las requisas obligatorias de caballos y mulas para el ejército, porque daban muy malos resultados, auspiciando, en su lugar, la crianza de ganado caballar y mular (SERAYLAN LEIVA, 1989, p. 676).

Por tanto, si bien es cierto que los ejércitos saquearon, reclutaron a la fuerza y cometieron innumerables abusos, frecuentemente tuvieron que atenerse a lo que los campesinos aceptaban darles a sus combatientes ya que el Estado carecía de la capacidad coercitiva que habría de adquirir más tarde, con un ejército institucionalizado. Los caudillos dependían así de pobladores con destrezas y recursos específicos. En la guerra civil de 1834, por ejemplo, generales criollos y aristócratas, héroes de la independencia, e incluso un presidente del país, llegaron a implorar a campesinos quechuahablantes iletrados -de quienes hacía poco se habían mofado llamándolos "indios traidores realistas" y "borrachos"- a que se sumaran al bando liberal para defender al Estado de un golpe, lo cual lograron con éxito (cf. MÉNDEZ G., 2001; 2004; 2005, especialmente cap. 7) ${ }^{15}$.

Tan extremo es el argumento de que todo se obtuvo a la fuerza en estas guerras como la idea de que los campesinos colaboraron con los militares gracias a un "patriotismo natural".

15 Pese a que desde hace varios lustros se han venido publicando investigaciones que dan cuenta de la participación campesina en las contiendas políticas del siglo XIX (RIVERA SERNA, 1958; DUNBAR TEMPLE, 1971; VERGARA ARIAS, 1973; MÉNDEZ G., 1996; 1997), algunos investigadores han seguido afirmando que el campesinado peruano sólo despertaría a la "conciencia nacional" sólo con la Guerra del Pacífico. Este es, por ejemplo, el parecer de Mallon, quien es, irónicamente conocida por sus estudios sobre campesinado y nación. Escribe Mallon: "Only with the War of the Pacific and the crisis of the Chilean occupation (1881-1884), would opportunities open up for indigenous and village montoneras to participate in defending and redefining the nation" ["Somente com a Guerra do Pacífico e a crise da ocupação chilena (1881-1884) surgiriam oportunidades para os indígenas e as vilas montoneras participarem na defesa e na redefinição da nação" - N. R.] (MALLON, 2002, p. 24). 
Ambos argumentos han obstruido la comprensión del proceso mediante el cual la población civil legitimó la violencia, así como la disquisición de las razones pragmáticas que llevaron a las poblaciones a aliarse con uno y otro bando, algunas veces en forma de guerrillas, sin desmedro del sentido político que otorgaran a sus actos.

Esta dinámica cambió con la profesionalización del ejército y la consiguiente separación entre Ejército y población civil, que fue instituida a partir de 1896, durante la administración de Nicolás de Piérola. Con el apoyo de una misión militar francesa, el presidente impulsó la profesionalización de las Fuerzas Armadas, mediante la creación de escuelas militares y el establecimiento del servicio militar. De allí resultó una planta de soldados y oficiales de tiempo completo. A medida que el Ejército se fue convirtiendo en una institución más centralizada y dependiente del presupuesto nacional, las sierras rurales empezaron a perder el lugar central que habían tenido en las contiendas nacionales desde las guerras de independencia. La ironía de este proceso reside en el hecho de que el presidente responsable de la profesionalización de las Fuerzas Armadas y del fin de la era de las guerrillas y las montoneras, Nicolás de Piérola, llegó al poder en 1895 impulsado por un movimiento montonero masivo.

El mundo que se formó en la sierra en los años que siguieron a la administración de Piérola, es decir, los primeros años del siglo XX, es de alguna manera más fácil de aprehender que aquel que dejó atrás, porque es más familiar para nosotros. Las nuevas instituciones y escuelas militares crearon espacios desde los cuales los militares empezarían a concebirse a sí mismos como una institución separada de los civiles y del mundo rural. Así, los militares comenzaron a percibir a los campesinos como personas que era necesario civilizar e integrar a la nación, no mediante la guerrilla, o el pago del tributo indígena, sino por medio del servicio militar y las escuelas que llegaban junto con las carreteras y la modernidad.

Por tanto, en el transcurso del siglo XX, un Estado más centralizado, ahora en comando efectivo del monopolio de la fuerza, relegó a cualquier guerrilla o montonera que pudiera emerger al reino de la ilegitimidad, esto es, hasta que la guerra de Sendero Luminoso entre 1980 y 1999 - que alcanzó cifras de casi 70000 muertos, la mayor parte de ellos campesinos quechuahablantes - revertió al país a una situación de guerra civil análoga a la que había caracterizado el siglo XIX: nos referimos a alianza que tuvo lugar entre el campesinado y el ejército para derrotar a la insurgencia. Esta alianza, demandada por los campesinos y fomentada (algo tardíamente) por el Estado rompió con el monopolio de la violencia legítima que habían ejercido las fuerzas armadas a lo largo del siglo XX y llevó al país a un estado de guerra civil similar al que había experimentado durante el siglo XIX. Es decir, un estado en que los jefes políticomilitares o caudillos, compensaban la insuficiencia del ejército de línea (esto es, el ejército regular) mediante la movilización armada de los pobladores civiles en forma de guerrillas y partidas, que asumieron las funciones represivas del Estado, aplacando insurrecciones y ejerciendo control social ${ }^{16}$. De manera similar, en la década de 1990 el Estado se apoyó en campesinos armados - los llamados ronderos - para derrotar a Sendero. De esta manera los civiles armados - a semejanza de los ronderos actuales - no constituían precisamente una amenaza en contra del gobierno, sino que más bien ayudaron a reforzar su legitimidad.

El registro documental del Archivo Histórico Militar - insuficientemente atendido por los historiadores - proporciona una ventana privilegiada hacia el mundo previo a la centralización y profesionalización del Ejército, un mundo en que los límites entre lo civil y lo militar eran aún difusos. Las observaciones que siguen son el resultado de un examen preliminar de esta documentación, particularmente aquella correspondiente a la Sierra Central durante la primera campaña por la independencia, dirigida por el General José de San Martín entre 1821 y 1823. Esta zona fue el teatro final y decisivo de las guerras de independencia sudamericanas y proporciona, por tanto, la documentación más rica.

Se trata de cartas oficiales y documentos de guerra intercambiados entre los oficiales de altos rangos y ministros de guerra y jefes militares de las más diversas graduaciones en diferentes

16 Hemos estudiado estas situaciones específicamente para la provincia de Huanta (cf. MÉNDEZ G., 2005, cap. 1, 7, Epílogo). 
regiones del Perú. Llaman la atención sobre todo los documentos intercambiados entre las autoridades militares que se acaba de mencionar y las autoridades locales civiles tales como gobernadores y alcaldes, incluso, de los más remotos pueblos. Los textos, consignados a veces en pequeños pedazos de papel, y en un castellano fuertemente impregnado de una fonología y sintaxis quechuas, transmiten conmovedoramente la urgencia, entusiasmo, desesperación, o frustración en los que fueron escritos, de acuerdo al caso. La documentación de este archivo es complementada otra procedente del Archivo General de la Nación, en Lima y el Archivo Departamental de Ayacucho y fuentes colecciones documentales publicadas.

El patrón que siguieron estas campañas militares fue inspirado por la guerra librada en España contra la invasión napoleónica ${ }^{17}$. En dicha guerra el ejército regular promovió la formación de guerrillas y partidas ${ }^{18}$ entre la población civil, principalmente en las zonas rurales ${ }^{19}$. Estos ejércitos irregulares debían apoyar al ejército de línea (es decir el ejército regular) en formas muy variadas, que abarcaban por ejemplo el aspecto logístico del avituallamiento, la obstrucción de caminos para repeler los avances de las tropas enemigas, e impedir que el ejército oponente accediera a recursos. Por ello, la guerra de partidas se llamó también "guerra de recursos"20. En otros casos, las guerrillas apoyaron al ejército regular

17 En España se produjeron varios manuales que reglamentaron la forma de organizar guerrillas entre 1808 y 1814. Estos manuales fueron reproducidos en América e inspiraron otros semejantes. Cf. por ejemplo Archivo Militar de Segovia (1808, f. 6); para los ejemplos americanos, cf. Leiva, Vega y Valcárcel (1989).

18 "Guerrilla" y "partida" se usaron muchas veces como sinónimos pero "partida" tenía otras connotaciones además de la militar.

19 Los llamados "cuerpos cívicos" se formaron en las zonas urbanas.

20 En Enero 4 de 1821, desde el Cuartel General de Retes, José de San Martín escribía al Gobernador Intendente de la Provincia de Tarma Don Francisco de Paula Otero lo siguiente: “[...] por pretexto alguno comprometa una accion formal con los enemigos, y solo debe Vuestra Señoría ceñirse á una guerra de recursos, tanto mas ventajosa en un Pais donde se tiene la opinión de sus habitantes, que sabiendolos dirigir con actividad, y juicio, es imposible que el Ejército mas numeroso y aguerrido pueda asistir a mediante el combate propiamente dicho.

Es importante resaltar que si bien las unidades guerrilleras eran entrenadas por oficiales del ejército, quienes las comandaban en las bases eran las autoridades civiles locales, constituyéndose así en nexo crucial con los altos jefes militares. Tales autoridades fueron en la sierra central, los alcaldes y gobernadores de los pueblos, dada la preponderancia de la organización comunal en la zona, mientras que en otras zonas fue clave la intermediación de hacendados y notables ${ }^{21}$. En las campañas de la sierra central los más altos jefes militares, tales como San Martín, Álvarez de Arenales y Francisco de Paula Otero, fueron muy conscientes de la necesidad de asignarles la organización de guerrillas a los oficiales que conocieran el área y las poblaciones especialmente bien.

El cúmulo de evidencias sugiere, así, que la guerra no hubiera sido posible sin gobierno, más específicamente, sin gobierno local. En efecto, a pesar de que convencionalmente la guerra tiende a ser asociada con caos y anarquía, en este periodo temprano los oficiales del ejército se apoyaron enormemente en una población civil organizada. La intervención de alcaldes y gobernadores fue absolutamente crucial para movilizar a los pueblos hacia la lucha, según puede deducirse de la cantidad de misivas que intercambiaron estas

ella: partidas cortas, la que mas de cien hombres mandadas por patriotas de alguna intilegencia y con conocimientos del terreno donde hacen la guerra: ostilizando el enemigo con preferencia por sus costados y retaguardia, deben hacerlo sucumbir en el termino / de dos meses" (DUNBAR TEMPLE, 1971, p. 186-187). Años después esta misma estrategia siguió empleándose. Por ejemplo, estando en Lima, el 8 de Junio de 1837, en medio de otro conflicto civil, el general Andrés de Santa Cruz daba instrucciones a Domingo Nieto para "hacer la guerra de partidas y recursos a ejemplo de lo que hicieron los españoles y los rusos a los franceses" (MCEVOY \& RENIQUE, 2010, p. 547), a la cual se refiere luego como "la más segura" (idem, p. $550)$.

21 En otras zonas como en la costa de Lima se trató de incorporar a la lucha guerrillera a grupos previamente armados, como por ejemplo a bandoleros. Estas prácticas fueron probablemente inspiradas por las disposiciones del Estado español que se dictaron en 1808, con miras a la formación de guerrillas que repelieran la invasión napoleónica mediante el otorgamiento de incentivos a los contrabandistas y otros personajes fuera de la ley (cf. ARCHIVO MILITAR DE SEGOVIA, 1808). 
autoridades y los ofíciales militares para coordinar las acciones más diversas. ¿De qué otro modo, si no mediante las autoridades locales, habrían podido convencer los oficiales que llegaban de lugares tan distantes como Jujuy y Tucumán, a los peruanos de luchar en la campaña de San Martín? Aún Lima podía permanecer en una situación de desgobierno y confusión, pero el gobierno local fue esencial para el éxito de las campañas de la independencia, y lo volvería a ser para la supervivencia del ya instalado Estado republicano, en la décadas siguientes (MÉNDEZ G., 2005, cap. 5, 7, Epílogo).

Las autoridades locales no sólo coordinaron movimientos militares con los oficiales y organizaron su base logística, sino que, en algunas zonas, se encargaron de la recolección de los diezmos para las finanzas militares, lo cual requería un gran despliegue organizativo (idem, cap. 2, 6-7). Los alcaldes incluso, se pusieron a la cabeza de sus respectivas guerrillas, tanto de los ejércitos patriotas como de los realistas. Los alcaldes que tomaron el bando independentista se llamaron a sí mismos, "alcaldes de la patria" mientras aquellos que apoyaban al rey se denominaron "alcaldes constitucionales" (CEHMP-AHM, 1822a).

Ambas denominaciones remiten a la lucha por la legitimidad que los dos bandos pretendían ganar. El término "constitucional" aludía a la Constitución liberal española de 1812 que tuvo una amplia acogida en América, incluso mediante proclamas en quechua 22 . Es probable que mediante la designación de "alcalde constitucional”, los oficiales realistas buscaran

22 Esta constitución extendía la ciudadanía española a los "hombres libres" de las colonias españolas de ultramar, incluidos los indígenas. Véase algunas proclamas de la constitución de 1812 y de los decretos liberales de las cortes de Cádiz en lenguas indígenas en Rivet y CréquiMontfort (1951). Sobre el impacto de la Constitución de 1812 en las poblaciones indígenas del Perú son pocos los estudios que se realizaron después del trabajo pionero de Christine Hünefeldt (1978), pero véase Sala Vila (19921993). Fuentes oficiales refieren que en tiempos de Abascal se repartieron unos 4000 ejemplares de la Constitución en el virreinato del Perú. La cifra puede ser exagerada, pero hay fascinantes evidencias rituales de la proclamación de la constitución en algunos pueblos andinos (cf. MÉNDEZ G., 2005, cap. 4; para el caso de Quito, cf. RODRÍGUEZ ORDÓÑEZ, 2005; cf. también IGUE, 2009). enfatizar que sus fuentes de legitimidad también provenían de los mismos pobladores locales.

Hacia la misma época, sin embargo, los republicanos preparaban la formación de su propio congreso y de una constitución política republicana en el Perú, lo cual permite suponer que la apropiación de ciertos términos correspondía a la mencionada lucha política por la legitimidad, se daba también en el campo del lenguaje de la guerra. En cualquier caso, la adopción de la etiqueta "constitucional" por las autoridades de los pueblos quechuahablantes que favorecían a los españoles fue muy rápida, como atestiguan los fuertes trazos de fonética quechua en una carta firmada por Santiago Muneves [Munívez], quien se identificaba a sí mismo como "yo yo, el alcalde constetuceonal del pueblo de Santiago de los Chongos" (idem, f. 2). Este es uno de los muchos casos que podría citarse.

Al resaltar su identidad como "alcaldes constitucionales", las autoridades de los pueblos de la sierra central que favorecían a los realistas muy probablemente intentaban deslegitimar la autoridad de los llamados "alcaldes comisionados" que eran nombrados por los oficiales que favorecían la independencia. Los alcaldes de este bando, sin embargo, parecían estar más a gusto con el apelativo de "alcaldes de la patria". De forma similar, los documentos contienen denominaciones como "partidas por la patria", "gobernadores de la patria" 23 .

Tal como fue usado el término en los documentos de guerra que hemos observado, "patria" transmitía menos la idea de un territorio "nacional" que la idea de soberanía. Quienes se declaraban "patriotas" o "patrianos" eran conscientes de estar apoyando una posición de

23 Para una ilustración de las diferentes denominaciones que recibieron las autoridades locales y, en especial, los alcaldes, veáse las comunicaciones enviadas por Tadeo Telles, Sargento Mayor del Ejército, Gobernador Político y Militar de Yauyos al Ministro de Guerra y Marina, 13 de Mayo del 1822. Entre ellas se adjuntan partes (algunos de ellos confiscados a los realistas) donde encontramos las siguientes referencias: "A los señores Alcaldes constitucionales del pueblo de Colca" y "Al Comandante Don Juan Evangelista Rivas, Comandante de Guerrillas por la Patria”. El 12 de Agosto de 1822 se adjuntan en el mismo expediente, partes firmado por "Alcalde nro 1 Santiago Muneves 'alcalde constetuceonal [sic]' de Santiago de los Chongos" e "Ildifonso [sic] Sosa Alcalde de la Patria" (cf. CEHMP-AHM, 1822b). 
ruptura con España que signaba el comienzo de una entidad política autónoma. Por tanto, el significado de "patria" en su sentido actual de "nación" habría empezado a tomar cuerpo apenas en el campo de batalla, tal como Thibaud ha argumentado para el caso de Venezuela (THIBAUD, 2003).

En otras palabras ni el bando de los "patriotas" ni el de los "realistas" estuvo conceptualmente definido antes de la guerra. Tanto para las bases civiles como para los oficiales militares ambos términos se fueron definiendo en el proceso de la lucha. Lo que sí estaba claro, es que a partir de 1822 - probablemente incluso desde 1821 -, en la sierra central, el término "patriota" dejó de referirse a la Monarquía española como había sucedido hasta hacía poco en toda Latinoamérica. El bando independentista y republicano se apropió así de la designación de "patriota". Por otra parte, si hubo un territorio asociado a la idea de patria, este no fue "nacional" sino continental, es decir, América. Esto se deduce de la prominencia con que se asocia a los "patriotas" con los "americanos" en la documentación de la guerra correspondiente al año 1822 en diversas regiones.

\section{LA SIERRA, ESPACIO CLAVE DE POBLA- CIÓN ORGANIZADA}

Todo lo dicho hasta aquí sugiere la necesidad de restituir en la historiografía el lugar que la sierra tuvo en la historia como un centro definitorio de la política nacional y de la constitución del Estado, un lugar que le ha sido arrebatado por la convicción limeñocéntrica de que fue un espacio marginal al devenir político nacional.. Sugerimos, en otras palabras, que el Perú no fue una excepción en el proceso de "ruralización del poder", que según Halperín, tuvo lugar en Hispanoamérica después de la independencia (HALPERIN DONGHI, 1969; 1991).

Un ejemplo claro de la importancia logística y estratégica de la sierra; en particular, la sierra central, lo constituyen los campamentos que los ejércitos establecieron en esta zona por órdenes de San Martín, en vista de los ricos recursos agrícolas y ganaderos de la región. ${ }^{24}$ Esta

24 Véase, por ejemplo, la "Instrucción de San Martín al General Álvarez de Arenales" (Pisco, 4 de Octubre, 1820) en de la Barra (1971, p. 357-358). El conocimiento del terreno y los recursos siguió siendo indispensable para decidir rutas del ejército y estrategias de guerra. Por estrategia siguió poniéndose en práctica en años posteriores. No es casual que la sierra sur-central se convirtiera en el teatro decisivo de las últimas campañas por la independencia. Esta región fue el granero de Lima y de los centros mineros que alimentaron la economía minera colonial. Tampoco es casual que estas mismas zonas hayan sido el último bastión de resistencia campesina frente a las tropas invasoras de Chile durante la Guerra del Pacífico y que haya sido igualmente codiciada por Sendero Luminoso en tiempos más cercanos a los nuestros.

En poco explorado territorio de la relación que las poblaciones campesinas de la sierra establecieron con los oficiales de ambos bandos quisiéramos rescatar un notable aporte del antropólogo Salomon. Se refiere a la cuestión del ganado, un recurso tan crucial en la guerra. En el pueblo de Rapaz, distrito de Oyón, en la sierra del departamento de Lima, Salomon descubrió, entre otros khipus de antigua data aún usados por los pobladores, uno muy distintivo que llevaba colgados dos figurines. Uno de ellos representaba lo que parecía ser un uniforme de gala usado por las tropas de San Martín - y luego por los ejércitos grancolombianos - en el Perú, y el otro representaba lo que parecía ser un montonero con su poncho. Luego de descartar una variedad de

ejemplo, el 18 de Agosto de 1842, el general Domingo Nieto escribía al General José María Plaza desde Huanta que si bien Huanta tenía abundante alfalfa, lo cual era bueno para la caballada, era preferible descansar en Huamanaga por ser "abundante en granos" (MCEVOY \& RENIQUE, 2010, p. 656-659). Para más ejemplos cf. McEvoy e Renique (2010, p. 549). Leiva (1989, p. 680) refiere que en 1842, "por razones de austeridad [...] [entre otras] se suprimió a la tropa - excepto a la de Lima - el socorro diario con el que pagaba su alimentación". Por tanto, "cuando se movilizaba el ejército, eran los pueblos de tránsito los que proporcionaban los alimentos al ejército, pero sólo hasta finalizar la campaña". Leiva autor añade que apenas en 1869 se incluyó en el presupuesto nacional el costo de la alimentación del soldado (ibidem). Sin embargo, la "guerra con Chile" fue otro momento de intensa formación de guerrillas, en que los ejércitos volvieron a depender de los pueblos para su subsistencia en campaña. Como lo reconoce el autor, la dependencia del ejército de bienes importados para su avituallamiento, incluso de alimentos en la era del auge del guano, causó serios problemas. Probablemente por ello se siguió acudiendo al apoyo de los pueblos con su producción local. Gran cantidad de estos centros de aprovisionamiento se encontraban en la sierra (cf. los mapas que proporciona LEIVA, 1989). 
interpretaciones, y cotejar con carbono catorce la evidencia de testimonios de los militares que sirvieron en la zona durante las campañas tanto de San Martín como de Sucre, Salomon concluyó que el khipu fue en efecto manufacturado en el marco temporal de las campañas militares de independencia (SALOMON, 2010).

Salomon sugiere que el khipu de los figurines, que él ha bautizado como el "khipu patriano", expresa una forma en que los pobladores de Oyón identificaban el ganado que era entregado a los ejércitos independentistas a su paso por esta provincia: primero a los ejércitos de San Martín y luego a los de Bolívar. Más interesante aún resulta el exorbitante número de 10000 cabezas de ganado, que según Salomon cuidaron los pobladores, a pesar de que no les pertenecía. Buena parte de este ganado provenía de otras comunidades y había sido salvaguardado o "escondido" en Oyón para que no fuera tomado por los realistas cuando estos atravesaran la zona. Confirmando el carácter crucial de la organización y del gobierno local para efectos de la guerra, que hemos subrayado hasta aquí, Salomon (idem, p. 23) escribe: "Since khipu were the characteristic rural way to keep track of herds, it is plausible that both those who yielded cattle to the 'patrianos' and those who were charged with caring for sequestered cattle would have kept cord records. A lapse in recordkeeping would have been a bad situation, because the very real possibility that the patriots might not pay for the animals they consumed was a threat to all parties. Caring for such huge numbers of guest cattle would have involved the services of many villages, and would demand strict coordination between 'Indian' village officers and patriot officers" 25 .

Otros testimonios dan cuenta de hasta 40000

25 "Como o khipu era a forma rural característica para pastorear, é plausível que tanto aqueles que criavam gado para os patrianos quanto aqueles responsáveis pelos cuidados com o gado seqüestrado deveriam manter registros de cordas. Uma falha na manutenção dos registros seria uma situação ruim, pois a possibilidade muito real de que os patriotas não pagassem pelos animais que tivessem consumido era uma ameaça para todos os envolvidos. Cuidar de números tão grandes de cabeças de gado envolveria as atividades de muitas vilas e demandaria uma coordenação cerrada entre os dirigentes das vilas indígenas e os dirigentes patriotas" (N. R.). cabezas de ganado que debían ser administradas por los pueblos durante la guerra ${ }^{26}$. El hecho de que en los Andes la riqueza no está dada naturalmente sino que depende de la capacidad de la sociedad para organizar y movilizar mano de obra - ya que la mayor parte de sus tierras son eriazas y su ecología debe batirse entre extremos 27 refuerza la idea de que la guerra no era posible sin gobierno local. Es decir, los oficiales en campaña dependieron de poblaciones organizadas de la sierra, no sólo para proveerse de recursos sino también para coordinar estrategias de guerra aprovechando las ventajas topográficas y geográficas del paisaje, y las técnicas de contabilidad y mnemotecnia de origen prehispánico que se pensaban extintas, como lo muestra la historia del khipu patriano elocuentemente.

Además de la abundante evidencia encontrada por Salomon acerca de intensas movilizaciones militares en el Oyón, así como de claros indicios de la adhesión de los pobladores a la causa independentista mediante el aporte de recursos, el antropólogo pudo establecer también su participación directa en las guerrillas. Esta lealtad descansaba aparentemente en la buena relación establecida en un momento temprano de las campañas militares con Álvarez de Arenales, uno de los generales más prestigiosos y de confianza del ejército de San Martín, en quien San Martín delegó el comando supremo de la sierra central desde 1820. Entre otras cosas Álvarez de Arenales creó un hospital y confió a los pobladores "equipos pesados"28. Dichas evidencias coinciden también con los vestigios del apoyo brindado a las tropas patriotas por otras regiones de la sierra

26 "El 30 de Agosto llegaron los enemigos que fueron al cerro trajeron como cuarentamil cabezas de ganado lanuda [sic] [...]". Este parte firmado por Antonio Aliaga se encuentra en las comunicaciones enviadas por Tadeo Telles, Sargento Mayor del Ejército, Gobernador Político y Militar de Yauyos al Ministro de Guerra y Marina, 12 de Agosto de1822 (CEHMP-AHM, 1822e). Otro ejemplo es la siguiente cita: "He dispuesto en vista de la necesidad que hay para el Exército de carne salgan quatro mil cabesas de este ganado correspondiente al estado en un número de cuarenta mil, que existen en estos sitios al cuidado de varios administradores" (Toribio Dabalos al Excelentísimo Señor, 1971).

27 Cf. el estudio clásico de Spalding (1984).

28 "Because Álvarez de Arenales wanted his troops to move quickly with light provisions, he left behind in Oyón the army's hospital, commissary, heavy equipment, and 
central, como es el caso de Yauyos, según los documentos que hemos encontrado en el archivo militar de Lima. Yauyos fue un foco especialmente militante de guerrillas (RIVERA SERNA, 1958; VERGARA ARIAS, 1973; BELTRÁN GALLARDO, 1977) ${ }^{29}$.

\section{REFLEXIONES FINALES}

Sugeríamos, al comienzar este ensayo, que el Perú adolece de una amnesia histórica en relación a sus guerras civiles decimonónicas. Nuestro propósito al rescatarlas del olvido es resaltar su importancia como dinámicas constructoras de tejido social y político. La interacción entre oficiales del Ejército y los pobladores de los pueblos campesinos durante estas guerras tiene que haber afectado la vida de estas comunidades de una manera que aún aguarda ser revelada por los historiadores y que resulta importante en el examen de la formación del Estado peruano en sus orígenes. Nuestro análisis subraya que las relaciones políticas tienen un sustrato material que no puede aislarse de la construcción de imaginarios colectivos. Sin las contribuciones tangibles de los pobladores a las guerras de independencia y guerras civiles posteriores un Estado soberano no hubiera sido posible. Es también sobre la base de estos aportes que los pobladores forjaron un su sentido de pertenencia (o no) en una comunidad política soberana, y negociaron sus derechos $\mathrm{y}$ obligaciones como ciudadanos.

Decíamos también que, a diferencia del Perú, otros países latinoamericanos sí tienen recuerdan sus guerras civiles decimonónicas. Pero estas memorias han sido asociadas en la historiografía con una historia de caudillos más que con una

accompanying family members [...]. In this way Oyón became something of an independentista township" (SALOMON, 2010, p. 22) (“Como Álvarez de Arenales queria que suas tropas movessem-se rapidamente com provisões leves, deixou para trás, em Oyón, o hospital, a intendência, o equipamento pesado e os familiares acompanhantes do exército [...]. Dessa forma, Oyón assumiu algo de uma cidade independentista" (N. R.)).

29 Particularmente ricas al respecto son las comunicaciones enviadas por Tadeo Telles (CEHMP-AHM, 1822d); las de Juan Antonio Álvarez de Arenales, General Jefe del Estado Mayor al General de los Ejércitos del Perú al Ministro de Guerra y Marina (CEHMP-AHM, 1822c); las de Francisco de Paula Otero, Coronel Presidente de Tarma al Ministro de Guerra y Marina (CEHMP-AHM, 1822b). Véase también la abundante recopilación de Dunbar Temple (1971). historia de Estados. Argentina y Venezuela, por ejemplo, han sido estigmatizadas como tierras de caudillos y "tiranías" en la literatura anglosajona, una imagen que estos países han hecho suya. Probablemente debido a la influencia de Domingo Faustino Sarmiento y a sus epígonos, Argentina ha sido considerada (equivocadamente) el paradigma del "caudillismo latinoamericano" 30.

Como una reacción a estas historias de "caudillos bárbaros", y supuestamente contrarios a toda institucionalidad - y coincidiendo con el retorno de la democracia tras una era de dictaduras militares - surgió hace casi un par de décadas una explosión de trabajos que querían resaltar más bien el lado "civilizado" o, digamos, civil, de la política hispanoamericana. Estos estudios se centraron en las instituciones políticas, en los mecanismos de representación política y en la construcción de "espacios públicos", que existían en paralelo con las guerras ${ }^{31}$. Por otro lado, una mirada a los nuevos títulos permite establecer que la guerra y la revolución están de vuelta ${ }^{32}$.

El caso del Perú es diferente porque este país ha sido omitido, tanto en su propia percepción, como en la historiografía hispanoamericana, del paradigma de los caudillos bárbaros y las tiranías excesivas. Bolivia tiene sus propias discusiones

30 El libro de John Lynch (1992) ha contribuido a resucitar algunos mitos decimonónicos sobre el caudillismo latinoamericano, que designan a Argentina y a Venezuela como las tierras de los "caudillos paradigmáticos"; estos esquemas se replicarían "en pequeño" en los otros países, o al menos esto es lo que muchos han inferido. Lynch, como muchos otros, trata el "caudillismo" como si no estuviera ligado a la formación del Estado. Libros de texto de historia latinoamericana en los Estados Unidos siguen reproduciendo el mito romántico del caudillo héroe o del caudillo bárbaro debido, en parte, a la influencia que tuvo el estudio de Lynch..

31 Por ejemplo, los trabajos de Marta Irurozqui, Antonio Annino, Hilda Sabato, Marcela Ternavasio, Carlos Forment y Jorge Myers, entre otros.

32 Hay actualmente en toda América Latina un renovado interés por las revoluciones y las guerras. Este interés tiene que ver, en parte, con el auge de los estudios sobre nacionalismo y el papel de los sectores populares en la forja del Estado nacional en el siglo XIX. La literatura que empieza a florecer en Argentina es bastante rica. Aparte de los trabajos citados en la nota 3, arriba, cf. Ada Ferrer (1999), De la Fuente (2000), Di Meglio (2006), Fradkin (2006; 2008), Demélas (2007), Ratto (2007) y Mata (2008). 
al respecto (cf. IRUROZQUI, 2000). Como hemos sugerido al comienzo, el Perú del siglo veinte ha moldeado una identidad histórica que pasa por el recuerdo ambivalente de la insurgencia indígena de fines del xviII y la memoria de una guerra externa un siglo después, obliterando las guerras que se dieron entre ambos momentos. Ni siquiera las guerras de la independencia han logrado adquirir en el Perú el peso histórico, político y mediático de aquellos dos acontecimientos. Sirvan pues estas páginas como invitación a abordar el pasado peruano de un modo diferente, es decir, a la luz de un presente que todavía humea.

Pero al hacerlo no debemos perder de vista, parafraseando a David Lowenthal, que "el pasado es un país extranjero" (LOWENTHAL, 1985). El caso peruano, un país en el que las sierras rurales constituyeron el escenario central de la política y no los lugares marginales que han sido retratados tan largamente en el imaginario hegemónico de Lima. Tomar conciencia de que el pasado es diferente podría contribuir a desterrar estigmas racistas tan fuertemente asociados a los campesinos andinos y habitantes de la sierra en general - para no mencionar a los indígenas de la Amazonía - de ser "atrasados", "anti-Estado" y, en general, "obstáculos" para el desarrollo de la nación. Pero tomar conciencia de que el pasado es diferente no significa dejar de admitir que pueda volver, pues la historia nunca es lineal y los procesos de modernización y centralización del Estado pueden revertirse o truncarse, en formas difícilmente predecibles, como lo atestigua dolorosamente la guerra civil peruana más reciente.

Cecilia Méndez G. (mendez@history.ucsb.edu) é Doutora em História pela State University of New York (Estados Unidos) e Professora da Universidade da Califórnia, campus de Santa Bárbara (Estados Unidos).

Carla Granados Moya (c.granados@pucp.pe; historiaxx@hotmail.com) é Licenciada en Historia e historiadora de la Comisión Permanente de Historia del Ejército del Perú.

\section{REFERÊNCIAS BIBLIOGRÁFICAS}

BARRAGÁN, R. \& WANDERLEY, F. 2009. Etnografías del Estado en América Latina. Íconos, n. 34, p. 21-25, mayo. Disponível em: http://www.flacso.org.ec/docs/i34dossier.pdf. Acesso em: 18.maio.2012.

BASADRE, J. 1983. La historia de la república del Perú, 1822-1833. Lima: Universitaria.

BELTRÁN GALLARDO, E. 1977. Las guerrillas de Yauyos en la emancipación del Perú, 18201824. Lima: Editores Técnicos Asociados.

BONILLA, H. 1981. Clases populares y Estado en el contexto de la crisis colonial. In: (ed.). La independencia en el Perú. $\overline{2^{\mathrm{a}} \text { ed. }}$ Lima: Instituto de Estudios Peruanos.

BONILLA, H. \& SPALDING, K. 1972. La independencia en el Perú, las palabras y los hechos. In: BONILLA, H. (ed.) $L a$ independencia en el Perú. Lima: Instituto de Estudios Peruanos.

CAHILL, D. 1999. Violencia, represión y rebelión en el sur andino: la sublevación de Túpac Amaru y sus consecuencias.
Documento de trabajo n. 105. Lima: Instituto de Estudios Peruanos. Disponível em: http:// www.iep.org.pe/textos/DDT/ddt105.pdf. Acesso em: 18.maio.2012.

CENTENO, M. A. 2002. Blood and Debt: War and the Nation-State in Latin America. Philadelphia: Pennsylvania University.

DEMÉLAS, M.-D. 2007. El diario de José Santos Vargas 1814-1825. Lima: Plural.

DE LA BARRA, F. (comp.). 1971. Colección Documental de la Independencia del Perú. T. VI: Asuntos militares. V. 4: Estado Militar en 1820-1822. Lima: Salesiana.

DI MEGLIO, G. 2006. ; Viva el bajo pueblo! La plebe urbana de Buenos Aires y la política entre la Revolución de Mayo y el rosismo (1810 1829). Buenos Aires: Prometeo.

DUNBAR TEMPLE, E. (ed.). 1971. La acción patriótica del pueblo en la emancipación. Colección documental de la Independencia del Perú. V. 1, T. 5. Lima: Comisón del Sesquicentenario de la Independencia del Perú. 
EARLE, R. (ed.). 2002. Rumors of War: Civil Conflict in Nineteenth-Century Latin America. London: University of London.

ESCOBAR OHMSTEDE, A. \& FALCÓN, R. (eds.). 2002. Los ejes de la disputa: Movimientos sociales y actores colectivos en América Latina, siglo XIX. Madrid: Iberoamericana.

FERRER, A. 1999. Insurgent Cuba: Race, Nation, and Revolution, 1868-1898. Chapel Hill: University of North Carolina.

FRADKIN, R. 2006. La historia de una montonera: vandolerismo y caudillismo en Buenos Aires, 1826. Buenos Aires: Siglo XXI.

(ed.). 2008.¿Y el Pueblo dónde está? Contribuciones para una historia popular de la revolución de independencia en el Río de la Plata. Buenos Aires: Prometeo.

HALPERIN DONGHI, T. 1969. Historia contemporánea de América Latina. Buenos Aires: Alianza.

1991. Revolución y guerra: formación de una elite dirigente. Buenos Aires: Siglo XXI.

HÜNEFELDT, C. 1978. Los indios y la Constitución de 1812. Allpanchis Phuturinqa, Lima, n. 11-12, p. 33-57.

IGUE, J. L. 2009. Bandolerismo y etnicidad en las guerras de independencia: el caso de los morochucos de Cangallo, Ayacucho (18141829). Trabalho apresentado no Congreso Independencia y democracia en el Perú, realizado em Lima, em agosto de 2009. Digit.

IRUROZQUI, M. 2000. A bala, piedra y palo: la construcción de la ciudadanía política en Bolivia, 1826-1952. Sevilla: Diputación de Sevilla.

JACOBSEN, N. \& HURTADO, A. D. 2002. Montoneras, la comuna de Chalaco y la revolución de Pierola: la sierra piurana entre el clientelismo y la sociedad civil, 1868-1895. In: FALCÓN, R. \& ESCOBAR OHMSTEDE, A. (orgs.). Los ejes de la disputa: movimientos sociales y actores colectivos en América Latina, siglo XIX. Madrid: Iberoamericana.

JIMÉNEZ, E. 2009. Discurso de lanzamiento de la segunda edición del libro Chungui: violencia y trazos de memoria. Lima: Instituto de Estudios Peruanos.

LA FUENTE, A. 2000. Children of Facundo: Caudillo and Gaucho Insurgency during the Argentine State-Formation Process (La Rioja, 1853-1870). Durham: Duke University.

LÓPEZ-ALVEZ, F. 2000. State Formation and Democracy in Latin America, 1810-1900. Durham: Duke University.

LOWENTHAL, D. 1985. The Past is a Foreign Country. Cambridge: Cambridge University.

LYNCH, J. 1992. Caudillos in Spanish America. Oxford: Clarendon.

MALLON, F E. 2002. Decoding the Parchments of the Latin American Nation-State: Peru, Mexico and Chile in Comparative Perspective. In: DUNKERLEY, J. (ed.). Studies in the Formation of the Nation-state in Latin America. London: Institute of Latin American Studies.

MATA LÓPEZ, S. 2008. Los gauchos de Güemes: guerras de independencia y conflicto social. Buenos Aires: Sudamericana.

MCEVOY, C. 1997. La utopía republicana: ideales y realidades en la formación de la cultura política peruana, 1871-1919. Lima: Pontificia Universidad Católica del Perú.

2004. La huella republicana liberal en el Perú: Manuel Pardo, escritos fundamentales. Lima: Congreso del Perú.

2007. Homo politicus: Manuel Pardo, la política peruana y sus dilemas (1871-1878). Lima: Oficina Nacional de Procesos Electorales.

MCEVOY, C. \& RENIQUE, J. L. (eds.). 2010. Soldados de la República: guerra, correspondencia y memoria en el Perú (18301844). T. I. Lima: Congreso de la República.

MÉNDEZ G., C. 1996. Rebellion without Resistance: Huanta's Monarchist Peasants in the Making of the Peruvian State: Ayacucho, 1825-1850. Phd Dissertation. New York: State University of New York.

1997. Pactos sin tributo. Caudillos y campesinos en el Perú postindependiente: el caso de Ayacucho. In: REINA, L. (org.). La 
reindianización de América, siglo XIX. Ciudad de México: Siglo XXI.

2000. La tentación del olvido: guerra, nacionalismo e historia en el Perú. Diálogos en Historia, Lima, n. 2, p. 231-248. Disponível em: http://www.cholonautas.edu.pe/modulos/ biblioteca2.php?IdDocumento $=0113$. Acesso em: 18.maio.2012.

2001. The Power of Naming, or the Construction of Ethnic and National Identities in Peru: Myth, History and the Iquichanos. Past and Present, Oxford, n. 171, p. 125-160, May. Disponível em: http://www.history. ucsb.edu/projects/histpublications/files/ 02723-power_of_naming_english.pdf. Acesso em: 18.maio. 2012

2002. El poder del nombre o la construcción de identidades étnicas y nacionales en el Perú: mito e historia de los iquichanos. Documento de trabajo n. 115. Lima: Instituto de Estudios Peruanos. Disponível em: http:// ww w.tuckersharon.info/sites/ tuckersharon.info/files/mendez.pdf. Acesso em: 18.maio.2012.

2004. Tradiciones liberales en los Andes: militares y campesinos en la formación del Estado peruano. Estudios Interdisciplinarios de America Latina y el Caribe, Tel Aviv, v. 15, n. 1, p. 35-63. Disponível em : http:// www1.tau.ac.il/eial/index.php?option=com content $\&$ task $=$ view\&id=376\&Itemid $=193$. Acesso em: 18.maio.2012.

2005. The Plebeian Republic: The Huanta Rebellion and the Making of the Peruvian State, 1820-1850. Durham: Duke University.

2006. Las paradojas del autoritarismo: Ejército, campesinado y etnicidad en el Perú: siglos XIX al XXI. Íconos, Quito, n. 26, p. 17-34, sept. Disponível em: http:// www.flacso.org.ec/docs/i26_mendez2.pdf. Acesso em: 18.maio.2012.

. 2008. The Proscribed Heroe: Silences Around Túpac Amaru. Trabalho apresentado no Colóquio Writing the Republic: Historical Writing in Nineteenth-Century Spanish America. Realizado em Warwick (Inglaterra), em novembro de 2008. Digit.

2009. Militares populistas: Ejército, etnicidad y ciudadanía en el Perú. In:
SANDOVAL, P. (org.). Repensando la subalternidad: miradas críticas desde/sobre América Latina. Lima: Instituto de Estudios Peruanos.

MENDIBURU, M. 1890. Diccionario históricobiográfico del Perú. Lima: T. Aguirre.

MONSALVE, M. 2005. Civil(ized) Society and Public Sphere Multiethnic Societies: Struggles over Citizenship Lima Peru (1850-1880). PhD Thesis. New York: State University of New York.

MÜCKE, U. 2004. Political Culture In Nineteenth-Century Peru: The Rise of the Partido Civil. Pittsburgh: University of Pittsburgh.

PAZ, G. L. (ed.). 2007. Las guerras civiles 18201870. Buenos Aires: Eudeba.

PRADO RUEDA, R. 2004. La historia de las guerras. Barcelona: Colombia.

RATTO, S. 2007. Indios y cristianos: entre la guerra y la paz en las fronteras. Buenos Aires: Sudamericana.

RIVERA SERNA, R. 1958. Los guerrilleros del Centro en la emancipación peruana. Lima: PL Villanueva.

RIVET, P. \& CRÉQUI-MONTFORT, G. 1951. Bibliographie des langues aymará et kicua, 1540-1875. Paris: Institut d'Ethnologie.

RODRÍGUEZ ORDÓÑEZ, J. 2005. Ciudadanos de la nación española: los indígenas y las elecciones constitucionales en el reino de Quito.In: IRUROZQUI, M. (org.). La mirada esquiva: reflexiones sobre la interacción del Estado y la ciudadanía en los Andes (Bolivia, Ecuador y Perú), siglo XIX. Madrid: Consejo Superior de Investigaciones Científicas.

SABATO, H. 2008. Buenos Aires en armas: la Revolución de 1880. Buenos Aires: Siglo XXI.

SALA VILA, N. 1992-1993. La Constitución de Cádiz y su impacto en el gobierno de las comunidades indígenas en el virreinato del Perú. Boletín Americanista, Barcelona, v. 33, n. 42-43, p. 51-70. Disponível em: http:// www.raco.cat/index.php/boletinamericanista/ article/viewFile/98587/146184. Acesso em: 18.maio. 2012 . 
SALOMON, F. 2010. Khipu from Colony to Republic: The Rapaz Patrimony. In: BOONE, E. \& URTON, G. (eds.). Their Way of Writing: Scripts, Signs, and Pictographies in PreColumbian America. Washington (D C): Dumbarton Oaks Research Library and Collection.

SÁNCHEZ, G. \& AGUILERA, M. (orgs.). 2001. Memoria de un país en guerra. Los mil días 1899-1902. Bogotá: Planeta.

SANDERS, J. E. 2004. Contentious Republicans: Popular Politics, Race, and Class in Nineteenth-Century Colombia. Durham: Duke University.

SERAYLAN LEIVA, A. 1989. Historia general del Ejército peruano. T. V: El Ejército en la república: siglo XIX. Lima: Comisión Permanente de Historia del Ejército del Perú.

SPALDING, K. 1984. Huarochiri: An Andean
Society Under Inka and Spanish Rule. Stanford: Stanford University.

THIBAUD, C. 2003. Repúblicas en armas: los ejércitos bolivarianos en la Guerra de Indepenencia en Colombia y Venezuela. Bogotá: Planeta.

TILLY, C. 1985. War Making and State Making as Organized Crime. In: EVANS, E.; RUESCHEMEYER, D. \& SKOCPOL, T. (eds.). Brining the State Back In. Cambridge: University of Cambridge.

VERGARA ARIAS, G. 1973. Montoneras y guerrillas en la etapa de la emancipación del Perú, 1820-1825. Lima: Salesiana.

WEBER, M. 1980. El político y el científico. Madrid: Alianza.

ZEITLIN, M. 1984. The Civil Wars in Chile. Princeton: Princeton University.

\section{OUTRAS FONTES}

AGN. 1831. Pobladores de San Miguel y Chilcas. AGN. Ayacucho, PL 11-96.

ARCHIVO MILITAR DE SEGOVIA. 1808. Reglamento para la organización de partidas de guerrillas. 28 deciembre. Archivo Militar de Segovia, Segunda Sección 10 a división, Cuerpos en General: guerrillas, legajo 154.

CЕНMP-AHM. 1822a. Carta de Santiago Munevez. 12 agosto. Legajo 35, letra T, documento 110. Lima: Centro de Estudios Históricos Militares de Perú-Archivo Histórico Militar.

1822b. Comunicaciones de Francisco Paula Otero. Legajo 35, letra O. Lima: Centro de Estudios Históricos Militares de PerúArchivo Histórico Militar.

1822c. Comunicaciones de Juan Antonio Álvarez de Arenales. Legajo 35, letra A. Lima: Centro de Estudios Históricos Militares de Perú-Archivo Histórico Militar. 1822d. Comunicaciones de Tadeo Telles. Legajo 35, letra T. Lima: Centro de Estudios Históricos Militares de Perú-Archivo Histórico Militar.

1822e. Comunicaciones enviadas por Tadeo Telles, Sargento Mayor del Ejército, Gobernador Político y Militar de Yauyos al Ministro de Guerra y Marina. 12 agosto. Legajo 35, letra T. Lima: Centro de Estudios Históricos Militares de Perú-Archivo Histórico Militar.

Toribio Dabalos al Excelentísimo Señor General Don José de San Martín, Protector del Perú. Huamantanga el 2 de octubre de 1821. 1971. In: DUNBAR TEMPLE, E. (ed.). La acción patriótica del pueblo en la emancipación. Colección documental de la Independencia del Perú, v. 1, t. 5. Lima: Comisón del Sesquicentenario de la Independencia del Perú. 


\section{PERU'S FORGOTTEN WARS: FORMATION OF THE STATE AND A NATION'S IMAGINARY}

Cecilia Méndez G. and Carla Granados Moya

Unlike other countries of the Americas, Peru lacks a national memory regarding its $19^{\text {th }}$ century civil wars. The latter has been eclipsed by the overwhelming memory of the Pacific War that Peru and Bolivia lost to Chile(1879-1883) The present essay aims to rescue the memory of the $19^{\text {th }}$ century Peruvian civil wars from oblivion, beginning with the wars of independence. The questions we ask are motivated by the recent history of war begun by Sendero Luminoso between 1980 and the end of the 1990s, in which Andean peasants took on the repressive functions of the State by taking up arms to defeat Senderista insurgency. This situation has interesting parallels with the $19^{\text {th }}$ century civil wars. We argue that the study of the $19^{\text {th }}$ century civil wars, in light of the more recent internal turmoil, provides a fertile opportunity to discuss notions of citizenship and belonging, the relationship between war and the making of the State, as well as the advantages and drawbacks of the Weberian concept of the State as an entity that monopolizes legitimate violence. We highlight the importance of the civil organization of rural populations over the course of the war and, in broader terms, the building of the State.

KEYWORDS: Peru; War; Civil War; National Identity; $X X^{\text {th }}$ Century; National State. 


\section{LES GUERRES OUBLIÉES DU PÉROU : LA FORMATION DE L’ÉTAT ET DE L'IMAGINAIRE NATIONAL}

\section{Cecilia Méndez G. et Carla Granados Moya}

Contrairement à d'autres pays américains, le Pérou n'a pas une mémoire nationale de ses guerres civiles du XIX siècle. Ces guerres là se sont effacées à cause du fort souvenir de la Guerre du Pacifique, où le Pérou et la Bolivie ont été vaincus par le Chili (1879-1883). Cet article propose de sauver de l'oubli les guerres civiles péruviennes du XIX siècle, en commençant par les guerres de l'indépendance. Les questions ici posées sont motivées par la récente guerre qui a déclenché le Sendero Luminoso entre 1980 et la fin des années 1990, quand les campagnards des Andes ont assumé les fonctions répressives de l'État, en prenant les armes pour vaincre l'insurrection senderista. Cette situation exhibe des comparaisons intéressantes avec les guerres civiles du XIX siècle. Nous suggérons que l'étude des guerres civiles du XIX siècle du Pérou, à la lumière de la récente guerre intérieure, offre une grande opportunité pour discuter les notions de citoyenneté et appartenance, la relation entre la guerre et la constitution de l'État, ainsi comme les limites du concept wébérien de l'État comme l'être qui monopolise la violence légitime. Nous soulignons l'importance de l'organisation civile des populations rurales à la naissance de la guerre et, plus largement, dans la construction de l'État.

MOTS-CLÉS : Pérou; guerre; guerre civile; identité nationale; XIXè siècle; État national. 